\title{
MÍDIA, RELIGIÃO E GLOBALIZAÇÃO: A REPRESENTAÇÃO DA MULHER NO PENTECOSTALISMO DIGITAL
}

\author{
Matheus Machado Vieira ${ }^{1}$
}

\begin{abstract}
Resumo: O objeto dessa discussão foi pensado dentro de uma perspectiva teóricometodológica no que concerne às relações entre as expressões midiáticas da religiosidade pentecostal e os sentimentos na História. Os arcabouços que dão sustentação a essa análise são os fenômenos da globalização, do consumo e da propagação midiática: um cenário que atinge todas as formas de vida e expressões, entre elas a religião cristã. Por meio de duas lideranças pentecostais específicas, a pastora brasileira Sarah Sheeva e a escritora cristã estadunidense Stormie Omartian, é possível compreender conceitos concernentes a identidade, representação e sentimentos no que diz respeito a um modelo de mulher, família e sexualidade.
\end{abstract}

Palavras-chave: Consumo; Globalização; Mulheres; Pentecostalismo.

\section{MEDIA, RELIGION AND GLOBALIZATION: WOMAN REPRESENTATION IN DIGITAL PENTECOSTALISM}

\begin{abstract}
The object of the present discussion was thought in a theoretical and methodological perspective concerning to the relations between the media expressions of Pentecostal religiousness and the feelings in History. The frameworks that sustain this analysis are the globalization, consumption and media spread phenomena: a scenery that reaches all life and expressions forms, including Christian religion. By means of two specific Pentecostal leaderships, Brazilian Reverend Sarah Sheeva and American Christian writer Stormie Omartian, it is possible to comprehend concepts concerning to identity, representation and feeling with regard to one model of woman, family and sexuality.
\end{abstract}

Keywords: Consumption; Globalization; Women; Pentecostalism.

\section{MEDIA, RELIGIÓN Y GLOBALIZACIÓN: LA REPRESENTACIÓN DE LA MUJER EN EL PENTECOSTALISMO DIGITAL}

Resumen: El objeto de esta discusión fue pensado dentro de una perspectiva teóricometodológica en lo que concierne a las relaciones entre las expresiones mediaticas de la religiosidad pentecostal y los sentimientos en la historia. Los marcos que dan sustento a este análisis son los fenómenos de la globalización, del consumo y de la propagación mediática: un escenario que afecta a todas las formas de vida y expresiones, entre ellas la religión cristiana. Por medio de dos líderes pentecostales específicos, la pastora brasileña Sarah Sheeva y la escritora cristiana estadounidense Stormie Omartian, es posible comprender conceptos concernientes a la identidad, representación y sentimientos en lo que se refiere a un modelo de mujer, familia y sexualidad.

Palabras Clave: Consumo; Globalización; Mujeres; Pentecostalismo.

\footnotetext{
${ }^{1}$ Doutorando em História pela Universidade Federal do Paraná (UFPR). E-mail: mattvieira@gmail.com 


\section{INTRODUÇÃO}

Nas últimas décadas, presenciamos o despertar de novas formas de viver e sentir a religião. O sentimento religioso, que até o alvorecer da modernidade circundava o poder das grandes instituições, não necessariamente é a norma nos dias atuais. O modelo descrito consistia numa forma institucional, hierárquica e portadora única de "verdades" sobre a fé. Em um contexto cada vez mais global, as maneiras de o sentimento religioso ser vivido pelos sujeitos passaram por mudanças significativas, sendo que o fiel se encontra cada vez menos dependente das instituições para viver sua crença.

No tempo presente ocidental, mais especificamente no Brasil e nos Estados Unidos, segundo Stewart Hoover (2014), a religião não desapareceu por completo, como previram muitos teóricos da razão, ela adaptou-se à sociedade de mercado e, nesse âmbito, encontrou maneiras de permanecer atuante, buscando novas estratégias de propagação. A religião na era global pode ser pensada por meio de alguns conceitos, entre eles o de globalização e o de consumo.

Assim como o sociólogo inglês Anthony Giddens (2012), compreendo a globalização como um processo não homogêneo que tem levado as sociedades a viver cada vez mais próximas umas das outras, em uma miscelânea de culturas, em um mundo a cada dia com fronteiras mais flexíveis. O fator que mais intensificou esse processo foi o desenvolvimento das tecnologias de comunicação e informação, as quais inegavelmente aumentaram a velocidade e o alcance das interações de pessoas.

Embora, no tempo presente, o fenômeno da globalização, em muitos aspectos, seja compreendido por meio das mudanças nos grandes sistemas econômicos, políticos e sociais, os efeitos dela também podem ser sentidos nas culturas e no espaço privado. A globalização afetou nossas vidas íntimas de várias maneiras; nosso cotidiano inevitavelmente foi alterado, na medida em que as forças globalizadoras entraram em nossos contextos locais, ou seja, nossas casas, comunidades, famílias, círculos de amigos e parentes, por meio das comunicações.

Mas não foram somente os meios de comunicação os responsáveis pela presença mais atuante da globalização. Podemos citar o contato pessoal com outros estilos de vida como uma segunda possibilidade de compreender esse processo. Para Stuart Hall (2003), a maior interação entre as pessoas, o contato com culturas diversas dentro de um mesmo país, a 
convivência de grupos com variadas formas de vida, principalmente no cotidiano dos grandes centros, possibilitou a convivência de múltiplas identidades.

No espaço global, as identidades não necessariamente convivem de forma harmônica. Antoine Dilhac (2014) cita as diferenças culturais, étnicas, sociais, de gênero e religiosas hoje existentes, as quais geram constantemente atritos entre si e, muitas vezes, produzem querelas e o sentimento de intolerância.

Cultura e identidade estão entre os conceitos que melhor podem definir, bem como compreender, o fenômeno religioso. Cultura, na perspectiva de Hall (1997), é analisada como um substantivo que organiza atividades, instituições e relações sociais. Em sua visão, cultura é uma categoria analítica que busca compreender as formas como o conhecimento se produz.

Nessa perspectiva, é um conceito responsável pela construção de identidades, representações e linguagens. Sendo as identidades culturais construídas, o sujeito é o resultado dessa construção, pois se relaciona com a sociedade e com as tradições nela existentes. Dessa forma, o sujeito define sua identidade perante a sociedade e através dos conhecimentos que dela adquire. Esses conhecimentos são as tradições, que podem ser perpassadas das representações e sentimentos. Assim, o sujeito recria as tradições conforme as suas necessidades históricas, políticas, sociais.

Dessa forma, não podemos ver as identidades como fixas, mas construídas por grupos sociais com o fim de definir papéis aos indivíduos. Não podemos encarar as identidades como algo estanque, dado e acabado, pois as pessoas as angariam ao longo da vida, por meio da cultura, a qual cria representações sociais de grupos e sujeitos. Não obstante, não podemos definir os indivíduos através de rótulos, como se viessem prontos para desempenhar o que os grupos a que pertencem desejam.

Dessa maneira, podemos pensar os sujeitos atuantes em grupos religiosos, entre eles os evangélicos do ramo pentecostal. Devemos levar em consideração a individualidade na gestão da crença, bem como os sentimentos e emoções desse sujeito que crê. $\mathrm{O}$ pentecostalismo é o exemplo mais bem acabado para a compreensão da autonomia do indivíduo que busca o conforto religioso para dar respostas às suas angústias.

O pentecostalismo constrói uma identidade cultural no sujeito. Este, ao se identificar com o mesmo, passa a se sentir parte de um grupo específico, que, por sua vez, por meio da crença, sente-se provido dos bens de salvação. Nessa perspectiva, o fenômeno religioso também pode ser compreendido por meio das práticas e representações, sociais ou coletivas, que os sujeitos fazem de si e dos outros. 
As práticas e representações não estão separadas das identidades sociais. Roger Chartier (1991) as problematiza como práticas que visam fazer reconhecer uma identidade social, exibir uma maneira própria de existir e significar; são um estatuto ou uma posição, formas institucionalizadas e objetivadas pelas quais "representantes" marcam o modo visível e perpétuo da existência de um grupo, comunidade ou da classe.

Instituições, como a religião e a família, são geradas por meio de um sistema de classificação; incorporam-se em formato de representações coletivas as divisões da organização social. Dessa forma, elas podem ser entendidas como: "[...] algo que dá sentido a uma coisa ausente, é a forma como os indivíduos por meio das práticas fazem reconhecer suas identidades, ou ainda, é a maneira como os sujeitos contraditoriamente constroem a realidade" (CHARTIER, 2002, p. 73). As representações auxiliam-nos muitas vezes na compreensão de modelos disseminados pelas instituições, como, por exemplo, a idealização de mulher, família e sexualidade postas como formas a serem seguidas por muitas denominações religiosas.

As lideranças religiosas muitas vezes definem suas representações de gênero e sexualidade, as quais se tornam normas dentro de grupos, dos quais podem ser exemplo os evangélicos pentecostais. Esses agentes religiosos, sempre que possível, utilizam sua autoridade de liderança oficial para exercer o poder de convencimento, fazendo uso do sagrado.

Além disso, as lideranças comunicam-se com seus enunciatários por meio de uma natureza dinâmica que visa produzir a crença em padrões e estilos de comportamento a serem seguidos, propagandeados e vendidos. Um processo diretamente ligado a uma cultura do consumo, presente na era da globalização.

O consumo tem sido uma das principais características do mundo globalizado e o que, em partes, fomenta o mercado religioso. O triunfo do discurso acerca do consumo se tornou cada vez mais presente a partir da segunda metade do século XX, e, com o avanço da globalização, se cristalizou por meio da publicidade. Assim, o consumo deixou de ser apenas o resultado do desenvolvimento econômico gerado pelo capital e assumiu uma posição social e cultural. Trata-se de algo que se ampliou nas décadas finais do século XX e início do XXI, principalmente pelo desenvolvimento e o alcance dos meios de comunicação de massa: a mídia.

Para Anderson Retondar (2007), a mídia dita tendências, constrói discursos e dinamiza o consumo, além de interagir socialmente com diversos grupos. Nesse espaço, a religião também passou a ser gerida pela ótica midiática e do mercado. A globalização e a 
sociedade de consumo demandaram novas estratégias e renovações por parte dos detentores da retórica religiosa.

Em um espaço cada vez mais conectado, indivíduos mais independentes em suas escolhas e ações foram perpassados por um turbilhão de possibilidades e tiveram a chance de escolher o que lhes agrada. Na ótica mercadológica, isso significa selecionar, consumir, gerir mercadorias e bens culturais. Na cultura do consumo, a religião tornou-se um produto como qualquer outro.

Por esse viés, os sujeitos que hoje buscam a religião, quando não satisfeitos, podem trocar, mudar, buscar algo que supra suas necessidades imediatas. Seguindo esse caminho de reflexão, entramos com uma discussão frequente dentro dos estudos sobre religião: o conceito de mercado religioso.

Para Mariz e Machado (2007), a globalização refletiu-se nas religiões na forma de um afrouxamento de fronteiras, de um reforço na privatização das escolhas religiosas e na busca de uma conexão com o espaço público secularizado. Segundo as autoras, esses processos inter-relacionados apontaram para a banalização das instituições religiosas e para uma crescente dificuldade por parte delas de manter seus adeptos dentro de um sistema único de crença e autoridade.

No Brasil, o pluralismo religioso tem se reforçado e adquirido esse caráter distinto, diríamos, mercadológico, a partir do momento em que o papel de grandes instituições, como a Igreja Católica e igrejas protestantes históricas ${ }^{2}$ foi enfraquecido. Nesse sentido, em meio a novas estratégias de propagar a religião, cresceu no país a demanda por outros segmentos religiosos, o principal deles foi o pentecostalismo.

A principal estratégia - e talvez a mais importante - dos pentecostais na difusão do discurso religioso foi e tem sido a mídia. Não somente a mídia convencional, a radiodifusão, mas, cada vez mais, a internet e as novas plataformas digitais. É perceptível o uso frequente desses meios por líderes religiosos, sendo uma das formas mais eficientes de propagar mensagens. Atualmente, inúmeras igrejas e pastores fazem das mídias seus canais de comunicação mais importantes. Entre os exemplos, podemos citar a pastora brasileira Sarah Sheeva e a escritora cristã estadunidense Stormie Omartian.

O discurso dessas duas lideranças religiosas busca atingir as mulheres, sendo suas pautas voltadas essencialmente a esse público. Por meio de aconselhamentos que ocorrem

\footnotetext{
${ }^{2}$ Protestantes históricos: Igrejas advindas da Reforma Protestante do século XVI destacam-se nesse segmento: os Luteranos, os Calvinistas, os Anglicanos, os Metodistas, os Presbiterianos e Puritanos.
} 
comumente em suas redes sociais, ambas também angariam fiéis e admiradores com a venda de seus livros e outros materiais através do uso das mídias.

\section{ATIVISMO DIGITAL, MULHER, RELIGIÃO E SEXUALIDADE NA ÓTICA DA PASTORA SARAH SHEEVA E DA ESCRITORA CRISTÃ STORMIE OMARTIAN}

Sarah Sheeva fez parte da Igreja Celular Internacional (ICI), em Copacabana, no Rio de Janeiro, até 2013. Hoje, independentemente, administra seu ministério. Em suas redes sociais, ela relatou seu processo de conversão ao cristianismo. Em testemunho, a pastora afirma que viu a imagem do Demônio durante o ensaio de um show que faria, de modo que, após o episódio, recorreu à oração e aceitou a Cristo ${ }^{3}$. A partir de então, a mesma colocou fím a sua vida "mundana" e "secular". Em oposição ao Diabo, Deus veio em primeiro lugar para a mesma.

Nos últimos anos, com ajuda da ICI, Sarah montou seu próprio ministério, o "Ministério Sarah Sheeva", sendo sua principal missão as palestras pelo Brasil, em que ministra cultos pela defesa da virgindade, da pureza e do recato feminino. Devido ao fato de tratar de questões concernentes à feminilidade, boa parte do seu público é de mulheres. Vinculado ao "Ministério Sarah Sheeva", a pastora criou o "Culto das Princesas". A principal função desse culto é doutrinar mulheres cristãs de todas as denominações evangélicas ${ }^{4}$ na prática da castidade, valorização do corpo, virtude, obediência e submissão, ou seja, Sheeva parte da premissa de que só é possível se realizar como mulher sendo uma "excelente mãe, esposa e praticando a castidade até o casamento".

O oposto desse modelo, segundo a pastora, seriam as mulheres ligadas à “depravação moral", mulheres que, nas palavras dela, "não se dão ao respeito". Notamos a defesa do recato e a negação da sexualidade como algo bem manifesto no discurso de Sheeva. Em suas palestras e aconselhamentos sentimentais pelo país, a pastora dissemina esses valores e, ao partir de uma perspectiva claramente autobiográfica, justifica suas defesas religiosas pela própria experiência pessoal antes da conversão. A pastora afirmou em seu relato de conversão

\footnotetext{
${ }^{3}$ O testemunho de Sarah Sheeva encontra-se disponível em seu site: http://www.sarahsheeva.com/, acessado em 1 abr. 2017.

${ }^{4} \mathrm{O}$ objetivo de alcançar todas as denominações por parte de Sarah Sheeva faz cair por terra a velha rigidez institucional das denominações e seus pregadores. Aqui se tem um público evangélico, no caso dos cultos específicos às mulheres já cristãs/convertidas, ou seja, não se busca a conversão, uma vez que as mesmas já são convertidas, mas um aperfeiçoamento na vida de uma mulher cristã. A frouxidão globalizante presente aqui é perceptível, acompanhado do interesse pelo consumo.
} 
que se considerava viciada em homens antes de encontrar a Deus; hoje, ela condena esse passado e tenta disseminar o oposto do que viveu. ${ }^{5}$

A história da escritora cristã Stormie Omartian se assemelha em muitos aspectos com a da pastora Sarah Sheeva. Stormie Omartian nasceu em Brentwood, Tennessee, nos Estados Unidos, em 1953. Em suas redes sociais, a escritora contou como sucedeu seu processo de conversão ao cristianismo Pentecostal.

A conversão aconteceu no início da década de 1970, por meio da influência de sua amiga evangélica Terry Harriton, com quem cantava na TV. Terry apresentou-a ao pastor Jack Hayford, reverendo da Igreja do Evangelho Quadrangular de Los Angeles (EUA), em um momento em que as crises depressivas de Stormie estavam no ápice. Stormie relata que a conversa com o pastor foi serena; ele lhe deu três livros e pediu que ela os lesse e voltasse uma semana depois para falar suas impressões.

Os livros tratavam sobre o funcionamento do mal, a realidade e o poder do Espírito Santo $^{6}$ e sobre o evangelho e João. Este foi o momento em que, segundo a autora, "Jesus entrou em sua vida". ${ }^{7}$ A conversão de Omartian, não se deu por um evento sobrenatural, como a de Sheeva, mas pelo intelecto e pelas sensibilidades despertadas pela leitura. Hoje, Omartian diz que se realiza como mãe, esposa e avó. É cristã assídua e membra da Igreja do Evangelho Quadrangular, em Nashville, capital do estado americano de Tennessee. Seus livros são sucesso de venda não só nos Estados Unidos, mas em grande parte do mundo.

Traduzidos para inúmeros idiomas, seus best sellers encontraram no mercado religioso brasileiro uma grande receptividade. Títulos como: $O$ poder da esposa que ora, $O$ poder da mulher que ora e $O$ poder da família que ora, são os exemplos mais populares do sucesso editorial de Omartian. Para divulgá-los, a escritora faz uso intenso das redes sociais, como o Facebook, o Twitter e o Instagram.

As produções escritas e midiáticas de ambas apresentam-se como um corpus documental no qual é possível encontrar a receptividade das propostas das religiosas por parte dos fiéis, algo que ocorre por meio da interação dos indivíduos nas redes sociais. Os seguidores de Omartian e Sheeva nas mídias compartilham, comentam, espalham textos,

\footnotetext{
5 Entrevista disponível em: http://sarahsheeva.wordpress.com/adoracao-musica-e-entrevistas/, acessado em 1 abr. 2017.

${ }^{6} \mathrm{O}$ contato direto com o Espírito Santo, o sentimento e o advento do milagre são características contundentes do universo pentecostal. A presença e a intimidade direta com Deus e entrega ao divino, as promessas para uma vida em transformação e o simbolismo do milagre perpassam o cotidiano desse segmento evangélico.

${ }^{7}$ Informações disponíveis no site pessoal da escritora: https://www.stormieomartian.com/story/
} 
vídeos e mensagens, um fenômeno comum em uma era de comunicação digital de constante interação entre os sujeitos ${ }^{8}$.

\section{PENTECOSTAIS, PENTECOSTAIS RENOVADOS E NEOPENTECOSTAIS}

Para compreendermos o discurso das religiosas em questão, torna-se pertinente conhecer um pouco as vertentes de suas igrejas. A origem de boa parte das igrejas pentecostais encontra-se nos Estados Unidos da América, entre as quais se inclui a denominação de que a escritora Stormie Omartian faz parte, a Igreja do Evangelho Quadrangular. No Brasil, as matrizes religiosas dessas igrejas migraram para cá desde o início do século XX.

Todavia não é a proposta deste artigo fazer um apanhado histórico de cada uma das denominações, e sim buscar compreender os eventos mais recentes das religiões evangélicas no país.

Nas últimas décadas, o campo religioso brasileiro sofreu significativas mudanças em seu quadro institucional, com o aumento significativo das igrejas pentecostais e neopentecostais. O que é necessário compreender é que as fronteiras entre ambas estão cada vez menos nítidas, principalmente quando nos referimos à doutrina e ao estilo de pregação.

Os pentecostais enfatizam experiências espirituais, como cura, exorcismo e profecia. Segundo Ricardo Mariano (1999), diferentemente dos protestantes históricos - luteranos, presbiterianos, anglicanos e batistas, os pentecostais acreditam que Deus, por intermédio do Espírito Santo e em nome de Jesus Cristo, continua a agir da mesma forma que no cristianismo primitivo, curando enfermos, expulsando demônios, distribuindo bênçãos e dons espirituais, realizando milagres, dialogando com seus servos e concedendo infinitas amostras concretas de seu poder supremo.

O pentecostalismo é um movimento de renovação dentro do cristianismo e coloca ênfase especial na experiência direta e pessoal com Deus. O que diferencia os pentecostais dos pentecostais renovados e neopentecostais é que os últimos pregam, entre outras coisas, o

\footnotetext{
${ }^{8}$ Ambas possuem perfis em redes sociais como Facebook, Twitter, Instagram e canais no Youtube. Tanto Sarah quanto Stormie conservam sites, blogs e perfis em redes sociais. Lá elas ministram aconselhamentos amorosos para mulheres solteiras e casadas com o intuito de "restaurar" casamentos, famílias, bem como aconselhar um comportamento sexual regrado. Sobre os livros de ambas, elas possuem uma significativa gama de publicações que podem ser trabalhadas de inúmeras formas. Esse material pode identificar as propostas de evangelização das religiosas. Já as mídias digitais, a recepção daqueles que buscam, interagem e consomem esse discurso.
} 
afrouxamento dos costumes, a teologia da prosperidade ${ }^{9}$ a guerra espiritual e o uso intenso das mídias.

Partindo da definição tipológica de Mariano (1999), uma abordagem de grande importância para compreendermos essas vertentes, podemos pensar nas definições a seguir.

Os neopentecostais são as denominações religiosas que surgiram no Brasil em meados da década de 1970, muito impulsionadas pela teologia da prosperidade e pela mudança de prioridades de fiéis e líderes religiosos.

Para o crente neopentecostal, o importante é a vida aqui e agora, ou seja, antes de viverem ao lado de Deus, nada mais justo que gozarem de uma vida de conforto e consumo. Contudo, esta vivência não se encontra desassociada dos preceitos religiosos manifestos nos textos bíblicos, portanto, não implica em abrir mão de algumas fronteiras morais, a exemplo da valorização do corpo, do casamento e de uma sexualidade contida.

\section{OS USOS DA MÍDIA: A ESTRATÉGIA DA RELIGIÃO NA ERA GLOBAL}

Um dos principais meios que levaram as igrejas a se adaptarem à sociedade globalizada foi a mídia e, segundo Stewart Hoover (2003), os múltiplos usos da tecnologia. Destacam-se, nesse contexto, as mídias digitais, as quais englobam as redes sociais, de uso muito comum, principalmente no cotidiano das culturas jovens. Esse fato não deixa de ser uma faceta coerente ao se pensar no público alvo da pastora Sarah Sheeva: a maioria é de mulheres jovens, entre dezoito e trinta anos, que se identificam com o discurso a elas direcionado.

Trata-se de fiéis conectadas às mídias, em que ouvem e compartilham músicas, textos, mensagens e vídeos de aconselhamento da líder. As fiéis também divulgam os cultos e os livros da pastora, o que demonstra a interação delas com o discurso religioso em um formato de transmissão, até a poucos anos, não convencional. $\mathrm{O}$ mesmo acontece com Stormie Omartian em suas mídias digitais, pois a escritora, além de postar mensagens de sua pregação diária da bíblia em sua página pessoal no Facebook, também divulga e vende livros de sua autoria, com os mais variados títulos, referentes à família e a modelos subjetivos de feminilidade cristã.

\footnotetext{
${ }^{9}$ Teologia da Prosperidade: é uma doutrina religiosa cristã que defende que a bênção financeira, segundo a mesma: É o desejo de Deus para os cristãos que a fé, o discurso positivo e as doações para os ministérios cristãos irão sempre aumentar a riqueza material do fiel, ou seja, bênçãos convertidas em graças materiais.
} 
Para Hoover (2003), a mídia desempenhou no passado e desempenha no presente um grande papel na propagação do discurso religioso. Em uma sociedade globalizada e mundialmente conectada, essa propagação ganhou novos formatos. A segunda metade do século XX assistiu à emergência da grande mídia ou, como aponta Douglas Kellner (2001), de uma "cultura da mídia".

O autor analisa a mídia como uma produtora de imagens, sons e espetáculos que ajudam a formar opiniões e comportamentos sociais, sendo que muitas vezes fornece material para as pessoas forjarem suas identidades. Segundo o autor, essa indústria cultural fornece modelos para que os indivíduos construam seus ideais de classe, etnia, gênero, sexualidade ou seja, o senso de "nós" e dos "outros".

Por esse pressuposto, podemos compreender a mídia como propagadora de valores morais e códigos comportamentais, algo que define o que é "bom" ou "ruim", "positivo" ou "negativo". Os pentecostais no Brasil, segundo Cunha (2007), desde meados dos anos 1950/60, fazem uso da mídia para difundir sua palavra, promover suas igrejas e fazer conhecidas suas lideranças religiosas.

$\mathrm{Na}$ história do protestantismo, a comunicação sempre foi um diferencial. Segundo Campos (2008), a revolução na comunicação cristã veio após a descoberta da imprensa no Ocidente, o que possibilitou que a percepção visual predominasse sobre a percepção auditiva, algo que as religiões reformadas a partir de então souberam absorver muito bem.

Mas que possibilidades a comunicação trouxe ao protestantismo e que mudanças ela promoveu e tem promovido? Campos (2008) é enfático ao dizer que a principal transformação para que os protestantes tenham se apropriado das mídias como ferramenta de evangelização foi o crescimento vertiginoso do pentecostalismo ao longo do século XX.

Tanto que, no cenário brasileiro pós-1980, os pentecostais começaram a se fazer presentes na mídia de forma mais frequente. Em um primeiro momento, compraram horários nas emissoras de rádio e, depois, nas madrugadas das emissoras de TV aberta. Essa presença pequena aumentou nas madrugadas, consideradas "horas mortas", para depois algumas igrejas conseguirem comprar e ocupar horários nobres na televisão.

Os maiores exemplos em relação ao "televangelismo" no Brasil estão no missionário Romildo Ribeiro Soares, da Igreja Internacional da Graça de Deus, que ocupa uma faixa no horário nobre da TV Bandeirantes. Na sequência, está a Igreja Universal do Reino de Deus, do bispo Edir Macedo, que ocupa um horário nobre na TV Gazeta, de São Paulo, e possui sua emissora própria de programação secular, a Rede Record de Televisão. Macedo também 
possui o jornal impresso Folha Universal, que está entre os impressos religiosos de maior circulação na América Latina.

De que forma o impacto midiático afetou a maneira como as pessoas interagem com a religião? Poderíamos dizer que em muita coisa. O fiel não necessariamente se desloca de casa para ter acesso à palavra divina. Muito menos precisa, rigidamente, frequentar cultos, seguir uma autoridade e hierarquia religiosas austeras, como havia sido o modelo das grandes instituições religiosas.

Magali Cunha (2007), em estudos sobre a difusão da mídia evangélica e seus reflexos sobre os fiéis, vê o impacto de forma mais eficiente no Brasil a partir da década de 1990, devido à difusão expressiva do comércio de bens simbólicos e uma inegável ênfase no consumo. Nessa linha, o consumo foi então o novo tratamento das lideranças destinado aos fiéis, tornando os cristãos um segmento de mercado importante no Brasil. Tanto que, com as inovações e os avanços da comunicação, foi possível os pastores desempenharem um papel eficiente no que concerne à forma de levar a mensagem religiosa:

[...] a mídia impressa procura acompanhar esse processo, por meio da oferta de revistas de variedades evangélicas. [...] na programação de rádio e TV e na literatura impressa a ênfase da mensagem transmitida não é na "Igreja" e na adesão a ela, mas no cultivo de uma religiosidade que não depende dela, mas que é intimista, individualizada. Elementos próprios da teologia gospel. O que se enfatiza não é a igreja, mas a experiência religiosa mediada pela TV ou rádio, isto é, o meio possibilita o cultivo da religiosidade, independentemente da adesão a uma comunidade de fé (CUNHA, 2007, p. 144-145).

Se o rádio e a TV desempenharam um papel dinâmico em suas formas de propagação na mídia evangélica e no cultivo de relações mais individualizadas com os fiéis, o meio digital se fez ainda mais amplo no que tange a essa questão. A partir do momento em que, nas plataformas digitais, o cristão tem a possibilidade de interagir, algo não viável na mídia convencional, os difusores dessas mensagens religiosas cada vez mais as buscam. Lá são criativos em seus estilos de divulgação, pois conseguem perceber os sentimentos e anseios dos fiéis.

Henri Jenkins (2009) parte de uma concepção hoje muito utilizada nos debates sobre mídia: a convergência. Para o autor, estamos em plena cultura da convergência, devido ao fato de as mídias digitais estarem ganhando espaço dentro daquilo que antes era monopólio da radiodifusão. Assim, a convergência, para Jenkins, é o reflexo imediato da era digital, na qual os meios de comunicação de massa tradicionais se fundiram com o digital. 
O resultado da convergência tem sido o compartilhamento de informações por uma legião de indivíduos. Hoje, qualquer pessoa pode espalhar ideias e interagir com grupos e pessoas pelas redes sociais. Mesmo as informações oficiais, que em outros tempos eram monopólios dos noticiários da grande mídia, atualmente, podem ser divulgadas e interpretadas de diversas formas.

A convergência dos meios de comunicação inegavelmente tem auxiliado as lideranças religiosas de inúmeras igrejas na visibilidade de seus cultos, mensagens e mercadorias. Por meio dela, os porta-vozes das igrejas buscam arregimentar um número cada vez maior de pessoas, ao mesmo tempo em que vendem seus produtos, valendo-se do consumo cristão. Tomemos a escritora cristã estadunidense Stormie Omartian como exemplo.

Omartian explora de forma incessante as mídias para divulgar seus livros, a maioria dos quais é best seller em vários países, inclusive no Brasil. Sarah Sheeva compartilha desse esforço de divulgação midiática de seus escritos, no entanto, sua ênfase maior está nos vídeos de aconselhamento sentimental e no "Culto das Princesas".

Muitos discursos de pastores evangélicos, além dos objetos deste artigo, circulam pela rede. No Brasil, existem inúmeros exemplos a serem citados, assim como nos Estados Unidos. Um dos pastores nacionais mais conhecidos na atualidade é Silas Malafaia, da Igreja Assembleia de Deus- Vitória em Cristo, que, além de seu programa televisivo diário, Vitória em Cristo, todas as manhãs das $8 \mathrm{~h}$ às $9 \mathrm{~h}$ na Rede Brasil, possui um site onde disponibiliza na íntegra seus programas para quem não pode acompanhar pela TV. Malafaia constantemente posta em suas redes sociais trechos do programa. ${ }^{10}$

Outro exemplo é a pastora e cantora gospel Ana Paula Valadão, da Igreja Batista da Lagoinha, em Belo Horizonte, Minas Gerais. Valadão, além de pastora e cantora, é uma líder religiosa atuante em diversos ministérios; entre eles, o culto específico que ela comanda só para mulheres, chamado "Mulheres diante do Trono". Valadão possui um canal oficial no YouTube, bem como perfis ativos no Facebook e Instagram. ${ }^{11}$

Um exemplo contundente para essa discussão é Sarah Sheeva. A pastora comandava um quadro no programa televisivo Manhã Maior, na Rede TV, de segunda a sexta-feira, das $9 \mathrm{~h}$ às $11 \mathrm{~h}$ da manhã. $\mathrm{O}$ quadro ocupava alguns minutos do espaço televisivo, nos quais a pastora respondia às perguntas de telespectadores: questões relacionadas a amizade, namoro,

\footnotetext{
${ }^{10}$ Site de Silas Malafaia: http://www.vitoriaemcristo.org/gutenweb/_site/gw-inicial/. Acessado em 6 fev. 2017.

${ }^{11}$ Site Oficial de Ana Paula Valadão: http://diantedotrono.com/. Acessado em 6 fev. 2017.
} 
casamento e sexualidade. Muitos trechos desse quadro encontram-se disponíveis no canal oficial da pastora no YouTube. ${ }^{12}$

Já nos Estados Unidos, a apropriação das mídias por religiosos vai além, pois se trata da terra natal dos "televangelistas", que hoje também migraram para as mídias digitais. Vejamos alguns exemplos. Joyce Mayer, escritora cristã, pastora e televangelista, montou junto ao marido seu próprio ministério na Igreja Luterana Sínodo de Missouri. Sua eficácia na propagação de mensagens, vídeos e divulgação de livros hoje ocorre principalmente pela internet. Tanto que, além de seu site oficial em inglês, existem versões para outros países devidamente traduzidas para os idiomas locais. ${ }^{13}$

No caso de Stormie Omartian, muito embora não seja pastora como Sarah Sheeva e os outros exemplos citados, ela possui um portal na internet com mensagens de fé, vídeos, citações bíblicas, divulgação de uma agenda diária, bem como um espaço reservado para o comércio de seus livros, o "Stormie Store". ${ }^{14}$

Todos esses exemplos sustentam o pressuposto de que as mídias, principalmente as digitais, têm sido o canal de comunicação que, nos últimos anos, de forma considerável, angariou um número significativo de igrejas, líderes religiosos e fiéis. Não obstante, é importante trazer um ponto não debatido na discussão até o momento, o conteúdo dessas mensagens religiosas. O que de fato elas propagam, compartilham ou reforçam? Que sentimentos transmitem? E em que as lideranças se agarram para defender determinados pontos de vista?

Temas relacionados a costumes, família e sexualidade constantemente geram polêmica no meio evangélico. Trata-se de conceitos que sofreram mudanças significativas com a globalização, com os movimentos feministas e, segundo Manuel Castells (2003), a consequente crise da família patriarcal. Como o indivíduo cristão envolto em uma sociedade com essas características dialoga com a pluralidade de sujeitos hoje visíveis?

\section{PLURALIDADE E SENTIMENTOS A PARTIR DO FENÔMENO RELIGIOSO}

Os debates sobre pluralidade e sentimentos na história abrangem estudos que buscam compreender a pluralidade étnica, política, religiosa, de gênero, bem como os sentimentos que

\footnotetext{
12 Trecho do quadro de Sarah Sheeva no programa Manhã Maior: https://www.youtube.com/watch?v=2QY2ynja-c5Y\&t=111s. Acessado em 6 fev. 2017.

${ }^{13}$ Site brasileiro de Joyce Meyer: http://www.joycemeyer.com.br/jmbrasil/engine.php. Acessado em 6 fev. 2017.

${ }^{14}$ Portal de Stormie Omartian: https://www.stormieomartian.com/. Acessado em 6 fev. 2017.
} 
as permeiam. São abordagens que visam desfazer classificações fundamentadas na divisão binária dos elementos. Brepohl, Capraro e Garrafoni (2012), partem da palavra "dicotomia" para compreender a pluralidade e os sentimentos na história. São conceitos que procuram desfazer os pares opostos tais como: razão/emoção, utopia/ideologia, masculino/feminino, dominante/dominado, objetivo/subjetivo, permanências/mudanças, confrontos/resistências.

Recusando generalizações por parte dos pesquisadores que investigam esses territórios, deve-se buscar conceitos que deem suporte para entender as experiências individuais e coletivas dos sujeitos na história, entre essas experiências, o sentimento religioso. Como se constrói a subjetividade do indivíduo que compartilha uma crença; que sentimentos estão imbuídos neste processo? Como o sujeito religioso cria suas representações em meio a um contexto de pluralidades culturais e de identidades como as existentes no mundo globalizado? Para pensar a religião por meio dos sentimentos, recorremos aos conceitos de Corrigan (2009) e Ansart (1978) na presente reflexão.

Corrigan (2009) busca compreender o papel dos sentimentos essencialmente na religião, todavia, na língua inglesa, o autor tem a preferência pela palavra emotions ao invés de feelings, sendo que, para ele, são pequenas as fronteiras entre ambos. Em seu viés analítico, a emoção sempre esteve presente na religião, de modo que podemos pensar a religião dentro dos movimentos religiosos atuais.

O autor vê na religião formas plurais de construção das crenças. Essas formas solidificam diferentes estados emocionais no sujeito, ou seja, no raciocínio do indivíduo, a visão de mundo não está apartada do sentimento religioso. Dessa forma, a função do pesquisador de religiões e religiosidades é buscar compreender os sentimentos, por meio de abordagens que possibilitem observar como eles se realizam e em que contextos.

Sheeva e Omartian são perpassadas do sentimento de pertencer a uma comunidade, um grupo religioso que compartilha um mesmo viés discursivo e emocional. Essa emoção muitas vezes pode ser sentida por meio de palavras propagadas por elas, pois, interiormente, ambas estão imbuídas do sentimento sagrado de difundir suas interpretações da bíblia.

Essa base solidificada pelo simbolismo sagrado e perpassado de inúmeras representações é o argumento em que, muitas vezes, líderes religiosos baseiam-se para defender seus pontos de vista. Entre eles, a forma como uma mulher deve se vestir, falar, se comportar, bem como agir sexualmente.

Sarah Sheeva, no "Culto das Princesas", extravasa um sentimento religioso de pertença e defesa bíblica, ao mesmo tempo em que constrói representações de um modelo 
ideal de mulher e família embasada em uma longa tradição do cristianismo. Omartian faz o mesmo através da escrita, pois elabora um estilo de comportamento, constrói por meio do sentimento religioso um modelo a ser seguido para as mulheres cristãs. O poder da esposa que ora, o maior sucesso de venda da autora, é um exemplo contundente.

O discurso religioso muitas vezes é sentido de maneiras adversas por aqueles que o recebem, ao mesmo tempo em que colabora na construção de diferentes representações. Assim, não é possível afirmar que seja hegemônico dentro de um grupo, pois dentro do grupo existem embates e discordâncias, algo visível no âmbito religioso.

Por conseguinte, os agentes religiosos tendem a operar formas diversas para disseminar mensagens, muitas vezes utilizando-se das emoções, das paixões e de técnicas de convencimento para que suas falas sejam reconhecidas por aqueles que os recebem. Pierre Ansart (1978) tem muito a nos dizer quando analisa as paixões humanas e as formas de retórica que muitos agentes usam para conquistar carisma dentro de um grupo.

Ao discutir as formas de difusão ideológica usadas por agentes detentores da palavra dentro dos grupos, Ansart busca compreender como os mesmos disseminam essas mensagens, e como elas são recebidas pelos enunciatários:

[...] o receptor é convidado a crer que adere as mensagens transmitidas por pura convicção e sem que os mecanismos e dispositivos de difusão tenham manipulado seu assentimento. Os produtores de mensagens não deixam de reforçar essa ilusão, uma vez que é de seu interesse surgir como os puros detentores da linguagem da verdade (ANSART, 1978, p.83).

Fazendo uma ponte com o discurso religioso evangélico, é possível compreender as formas de comunicação que as lideranças religiosas desse meio utilizam para transmiti-lo, bem como as formas de interpretação daqueles que o recebem. Estes, muitas vezes, estão imbuídos por um intenso sentimento de fé, o qual reforça a conotação de "verdade" das mensagens transmitidas.

Ansart complementa o raciocínio ao ver especificamente na linguagem religiosa um conjunto eficaz de mensagens, que, contudo, dificilmente abrange o todo em seu conjunto de significados. Para o autor, os diversos entes sociais possuem a sua própria linguagem, que muitas vezes destoa da fala religiosa, tais como políticos, chefes militares, artesãos, camponeses, comerciantes e todos aqueles que vivem em um grupo específico.

Todavia, para o grupo que compartilha a linguagem religiosa, que a proclama como algo sagrado, ela fornece um sentido eminente para as suas vidas, e é nesse ponto que, 
segundo Ansart (1978), os detentores da palavra (sacerdotes) esforçam-se para que todos aceitem e respeitem o conteúdo da doutrina por eles proclamada, mesmo que outros sujeitos dentro de uma sociedade não se encontrem nessa linguagem. É a partir de então que surgem os conflitos, as discordâncias, os proselitismos e, muitas vezes, a intolerância, algo que ocorre dentro de uma pluralidade de sujeitos.

Por meio dessa análise, é possível compreender os sujeitos dentro de uma sociedade plural, bem como os sentimentos neles imbuídos. Naqueles em que esse discurso possui uma finalidade, representações são consolidadas, linguagens solidificadas e, nesse ponto, surgem os conflitos com aqueles que não se sentem contemplados com determinadas enunciações; a religiosa é um exemplo.

A não aceitação da linguagem religiosa e da forma como em alguns momentos ela é colocada inevitavelmente tem levado ao surgimento de conflitos entre grupos religiosos e não religiosos. O sentimento da intolerância é o mais comum. Em um mundo globalizado, com uma convivência maior entre culturas e identidades, dificilmente a sociedade estaria isenta de conflitos culturais, étnicos, religiosos e sexuais.

Dilhac (2014) discute e historiciza o conceito de tolerância, colocando-o como essencial para vivermos em democracia, e também o critica como uma teoria política imperfeita. Segundo o autor, ao mesmo tempo em que a tolerância possibilitou a "liberdade de expressão", e deu voz a "todos" nas sociedades modernas, ela também abriu brechas para manifestações intolerantes.

Ao trazer essa discussão para a atualidade, o autor aponta que o valor sobre a tolerância é somente aparente e mascara um profundo desacordo filosófico e político sobre o sentido, as implicações, o peso e, portanto, os limites da tolerância. Ele levanta o seguinte questionamento.

[...] comment répondre aux demandes d'enseignement du créationnisme? Peut-on autoriser de manière cohérente la blaspheme et interdire les discours négationnistes? Est-ilégitime de montrer une bible dans un parlement pour soutenir un argument politique? Peut-on accepter des accommodements et des exemplions à la loi commune en raison d'engagements religieux? Doit on faire des lois pour interdire des pratiques vestimentaires parce qu'elles on tune signification religieuse? (DILHAC, 2014. p. 8). ${ }^{15}$

\footnotetext{
15 “Como responder às demandas do ensino do criacionismo? Pode-se autorizar de maneira coerente a blasfêmia e interditar o discurso negacionista? É legítimo mostrar uma Bíblia em um parlamento para sustentar um argumento político? Podem-se aceitar conciliações e isenções à lei comum por motivos de pertencimento religioso? Devemos fazer leis para interditar práticas vestimentárias por que elas têm uma significação religiosa". Tradução de Alexandre Cozer.
} 
Quando pensamos o espaço religioso atual com sua miscelânea discursiva sobre diversos temas, logo concordamos que, entre as muitas formas de viver na sociedade globalizada, algumas não necessariamente vão ao encontro dos discursos disseminados pela religião. Não é o objetivo dessa discussão trazer um debate sobre fundamentalismo religioso, mas entrecruzar o conceito de tolerância com algumas formas de comunicação religiosa que muitas vezes levam os sujeitos a praticarem atos intolerantes.

Dentro da gama significativa de denominações religiosas hoje existentes no Brasil, o poder da palavra autorizada por determinadas lideranças vem adquirindo, nos últimos anos, um status de guerra espiritual, guerra contra determinados grupos. É importante pensar de que forma esse embate intolerante dificulta o diálogo dentro da sociedade e das religiões com grupos que defendem os direitos das minorias.

Karina Bellotti (2012), quando analisa o cenário religioso brasileiro contemporâneo, observa um aumento significativo de igrejas e lideranças na conquista de influências no espaço público, bem como na política, tendo como exemplo as eleições presidenciais de 2010. Naquelas eleições, a então candidata Dilma Rousseff teve que desmentir, em uma declaração, que era a favor do aborto, para não perder apoio político de parte da bancada evangélica que a apoiava.

Segundo Paul Freston (1993), a formação de uma bancada evangélica no congresso nacional brasileiro é datada da Assembleia Constituinte, em 1986. Naquele ano, um número significativo de deputados evangélicos tomou posse na câmara; não se autodenominaram bancada naquele momento, mas já estavam conscientes de seu poder e influência sobre a população evangélica brasileira. Para Freston, foi um começo, mesmo que informal, de um crescimento significativo da influência não-oficial dos evangélicos junto à política nacional. ${ }^{16}$ Na presente discussão, o foco central não se concentra na política, mas não há como não citála, pois trata-se de uma via de acesso à influência evangélica no espaço público. Devido ao fato de o Brasil possuir uma bancada religiosa no congresso, votando projetos, propondo leis e legislando a vida de todos, inclusive de pessoas não religiosas, a problematização do

\footnotetext{
${ }^{16}$ As bancadas evangélica e católica no Congresso estão conversando sobre a possibilidade e apoio mútuo nas próximas eleições. Seu objetivo seria aumentar a representatividade, procurando refletir o tamanho que os cristãos têm na sociedade brasileira. A reportagem do Estado de São Paulo revela que é a primeira vez que há um diálogo maior para a união de forças. Os dois lados concluíram que possuem as mesmas bandeiras, que vão além de programas eleitorais, e isso irá fortalecer os valores cristãos. A expectativa é elegerem pelo menos 150 deputados e 15 senadores. Disponível em: http://politica.estadao.com.br/blogs/coluna-do-estadao/evangelicos-e-catolicos-se-unem-para-eleicao/ Acessado em $05 / 02 / 2018$
} 
proselitismo religioso dentro do "Estado laico" faz-se necessária, pois muitas vezes esses debates acalorados resignam-se à intolerância.

Obviamente, existem outros canais que podem esclarecer o sentimento de intolerância, como o carisma de muitos líderes religiosos, citando um caso análogo. Muitas vezes, esses líderes fazem uso de sua popularidade junto aos grupos para disseminar práticas e sentimentos intolerantes. Por essa via, as mídias têm sido de grande valor para eles, a partir do momento em que propagam discursos a um grande público amalgamado pelo carisma e pelo sentimento religioso.

Ao trazermos a discussão sobre intolerância para o presente objeto, é perceptível identificá-la tanto com Omartian quanto com Sheeva. Ambas, frequentemente, disseminam discursos que podem ser interpretados como intolerantes em relação a sujeitos que não pertencem aos seus grupos religiosos.

Como mencionado anteriormente, a sexualidade é onde o modelo tradicional resiste nas denominações pentecostais e neopentecostais, tanto que, nas interpretações de Omartian e Sheeva, o prazer sexual é uma benção de Deus e deve acontecer somente entre marido e mulher. Contudo, nós historiadores não podemos cair na armadilha de achar que essa enunciação seja uma exclusividade evangélica, pois ela é bíblica, datada das epístolas paulinas e durante séculos disseminada pelo cristianismo em algumas denominações religiosas, todavia, nem todas as lideranças cristãs são homogêneas ao interpretá-las. ${ }^{17}$

Ao resgatarmos o exemplo do "Culto das Princesas" de Sheeva ou mesmo os best sellers cristãos de Omartian, percebe-se a presença constante de modelos de proselitismo cristão, sendo que a principal defesa das religiosas são os valores referentes à castidade, valorização do corpo, virtude, obediência e submissão ao homem. O oposto disso são as mulheres não ligadas a esses valores, nas quais recai o sentimento de intolerância.

Quando um modelo de mulher, família e sexualidade é colocado como o único possível, outras formas que fogem a essa proposta se tornam marginalizadas. Sarah Sheeva (2015), em seu livro Defraudação emocional, denomina as mulheres não castas de "cachorras" e "piriguetes", pessoas ligadas ao que ela denomina de "depravação moral". Vejamos o posicionamento de Sarah Sheeva sobre a mulher que expõe o corpo nos vídeos de aconselhamento sentimental, em seu canal no YouTube:

\footnotetext{
${ }^{17}$ Paulo escreveu suas cartas dentro de uma cultura complexa, caracterizada pela interação entre os ambientes oral, retórico e literário. Será útil entender cada um desses ambientes e a interação entre eles, algo que é protagonizado por inúmeros pesquisadores e teólogos.

Mais informações em: https://editoraculturacrista.com.br/uploads/interpretacao-das-cartas-paulinas-trec.pdf Acessado em 05/05/2018
}

Fronteiras: Revista de História | Dourados, MS | v. 19 | n. 34 | p. 234 - 256 | Jul. / Dez. 2017 
Respondendo as perguntas e dúvidas enviadas por inúmeras mulheres cristãs, afirmo que a brecha do corpo deve manter-se fechada antes do casamento. Solteiro não é encalhado. Encalhado é quem casa com a pessoa errada, pois, vai ter que esperar a pessoa morrer para poder casar de novo, pois, segundo a bíblia casamento é até a morte e divórcio Deus odeia. Príncipes se atraem por princesas, cachorros por cachorras. Uma princesa jamais olharia para um homem comprometido, olhar para um homem comprometido é sinal de que a mulher está tendo um comportamento de cachorra. ${ }^{18}$

Semelhantes discursos são encontrados em vários livros de Stormie Omartian, produções dedicadas ao enquadramento da mulher cristã a uma moral específica no casamento cristão, textos em formato de orações:

Senhor afasta da vida do meu marido qualquer coisa ou pessoa que possa tenta-lo à infidelidade, ajuda-o a abster-se da prostituição, assim ele saberá possuir o próprio corpo em santificação e honra. Mostra-me como estar sempre atraente e desejável para ele, e como ser sempre o tipo de parceira que ele precisa. Oro para que nenhum de nós seja tentado a buscar satisfação em nenhuma outra fonte. [...] faznos sexualmente puros na mente e no corpo e fecha-nos as portas para todo o tipo de impureza sexual. ${ }^{19}$

Dessa forma, é notável a separação do "eu" e dos "outros" nas enunciações das duas líderes. O sentimento de pertença a uma verdade única permeia os discursos de ambas, o que inegavelmente leva à construção de representações ideais de mulher e ao sentimento de intolerância por aqueles que não compartilham dessa linguagem.

\section{CONSIDERAÇÕES FINAIS}

O objeto dessa discussão foi pensado dentro de uma perspectiva teóricometodológica que concerne às relações entre as expressões midiáticas da religiosidade e os sentimentos na História. No arcabouço que deu sustentação a essa análise, inegavelmente o fenômeno da globalização, do consumo e da propagação midiática envolveram o enfoque temático.

Buscou-se entender o viés significativo de uma política econômica de consumo, bem como os sujeitos na era da globalização, cenário que atinge todas as formas de vida e expressões, entre elas a religião. Aqui, foi debatida a religião cristã, foco central dessa análise. Também partiu-se da ideia de que a religião buscou se adaptar à globalização e ao consumo em um mundo cada vez mais secularizado. Todavia, conflitos eminentes surgiram dentro

\footnotetext{
${ }^{18}$ Declaração disponível em: http://www.youtube.com/watch?v=Wm_7qomqEZc Acessado em 31-07-2017.

${ }^{19}$ OMARTIAN, Stormie. O poder da esposa que ora. São Paulo: Editora Mundo Cristão, 2005.p. 28
} 
desse escopo de culturas, identidades, representações e sentimentos. O discurso intolerante pode ser considerado uma das principais consequências.

Como a liberdade sexual feminina pode ser questionada por muitos indivíduos envoltos em uma representação específica da mulher ${ }^{20}$ ? É o que procuramos responder ao longo do artigo. Não obstante, essa resposta veio da interpretação dos significados do discurso sobre aquilo que determinados sujeitos acreditam ser o correto.

O que existe além do sentimento de intolerância é a não aceitação de uma possível convivência harmoniosa entre grupos, pois os destoantes das representações religiosas compartilhadas são aqueles que precisam ser salvos, corrigidos dentro da visão daqueles que detêm a palavra da salvação. Trata-se de um sentimento de pertença que traduz, por meio das representações, uma possibilidade única de pensar a mulher, a família e a sexualidade.

As religiões evangélicas buscaram se adaptar ao espaço secularizado e multicultural da globalização. Inseriram-se na cultura do consumo e mesclam-se como uma identidade dentre tantas outras. Além dos conceitos desenvolvidos na presente discussão, o que permeou essa proposta, e irá permear uma pesquisa mais ampla, foram os usos das mídias, não somente por parte das lideranças evangélicas centrais, Omartian e Sheeva, mas por toda uma gama religiosa atual.

Procuramos trazer como os mesmos se apropriaram dessa ferramenta de comunicação, bem como se adaptaram às mudanças tecnológicas decorrentes nas últimas. Todavia, o que é importante nesse debate é o novo estilo de pregação por parte de muitas igrejas quando se apropriaram do uso dessas ferramentas midiáticas.

Trata-se de uma forma rápida e muitas vezes eficaz de disseminar a palavra, construir representações, gerir sentimentos e também propor modelos ideais para os cristãos na era do consumo. Com a globalização, a religião se tornou um bem a ser adquirido como qualquer outro produto.

Nessa perspectiva, o fiel não é mais preso a instituições fechadas e tradicionais, que não lhe possibilitavam uma maior interação com as lideranças e com os bens de salvação. A religião de consumo buscou reformular isso, pois propiciou uma maior proximidade do fiel com a mensagem sagrada. As mídias, principalmente as digitais, têm assegurado essa

\footnotetext{
${ }^{20}$ Recentemente tivemos o caso da "bela, recatada e do lar" matéria da Revista Veja referente a Marcela Temer; a polêmica demonstra como a discussão aqui apresentada está presente de maneira ampla na "cultura" brasileira, alicerçada no patriarcado. Disponível em: Disponível em: https://veja.abril.com.br/brasil/marcela-temer-belarecatada-e-do-lar/ Acessado em 05/02/2018.
} 
interação, pois as lideranças conquistaram esse território, bem como se adaptaram às mudanças advindas da cultura da conexão (JENKINS, 2014).

Para finalizar, resta-nos refletir que, muito embora as igrejas tenham modernizado suas formas de enunciação, dado uma nova roupagem ao discurso religioso, e os líderes tenham conquistado um maior carisma por meio das mídias, o conteúdo das mensagens permanece o mesmo em muitos quesitos. Quando pisamos no campo da moral e dos costumes, essas permanências são mais visíveis.

Nos temas referentes à mulher, à família e à sexualidade, nas vertentes cristãs contemporâneas, ainda há um intenso resgate da longa tradição cristã. Uma tradição que deve ser pensada pela longa duração, pois são princípios advindos do discurso bíblico, das epístolas paulinas e da forma como o cristianismo se consolidou.

\section{SITES CONSULTADOS}

http://www.humanas.ufpr.br/portal/historiapos/linhas-de-pesquisas/ Acessado em 22-01-2017. http://www.sarahsheeva.com/ Acessado em 01-02-2017.

http://sarahsheeva.wordpress.com/adoracao-musica-e-entrevistas/ Acessado em 01-02-2017. http://www.youtube.com/watch?v=Wm_7qomqEZc Acessado em 31-07-2017

https://www.stormieomartian.com/story/

http://www.vitoriaemcristo.org/_gutenweb/_site/gw-inicial// Acessado em 06-02-2017

http://diantedotrono.com/ Acessado em 06-02-2017

https://www.youtube.com/watch?v=2QY2ynjac5Y\&t=111s Acessado em 06-02-2017

http://www.joycemeyer.com.br/jmbrasil/engine.php Acessado em 06-02-2017

https://www.stormieomartian.com/ Acessado em 06-02-2017

https://veja.abril.com.br/brasil/marcela-temer-bela-recatada-e-do-lar/

Acessado em: 05/02/2018

https://editoraculturacrista.com.br/uploads/interpretacao-das-cartas-paulinas-trec.pdf

http://politica.estadao.com.br/blogs/coluna-do-estadao/evangelicos-e-catolicos-se-unem-para-eleicao/ Acessado em: 05/02/2018

\section{REFERÊNCIAS BIBLIOGRÁFICAS}

ANSART, Pierre. Ideologias, Conflitos e Poder. Tradução de Áurea Weissenberg. Rio de Janeiro: Zahar, 1978.

BELLOTTI, Karina Kosicki. "Fiéis soldados de Jesus Cristo" - discussões sobre o fundamentalismo no Brasil recente. IN: BREPOHL, Marion; CAPRARO, André Mendes; 
GARRAFONNI, Renata Senna (Orgs). Sentimentos na História: linguagens, práticas e emoções. Curitiba: UFPR, 2012.

BREPOHL, Marion; CAPRARO, André Mendes; GARRAFFONI, Renata Senna. (Orgs.). Sentimentos na História: linguagens, práticas e emoções. Curitiba: Editora da UFPR, 2012.

CAMPOS, Leonildo Silveira. Evangélicos e Mídia no Brasil: uma história de acertos e desacertos. Revista de Estudos da Religião - REVER. p. 1-26, setembro de 2008.

CASTELLS, Manuel. $O$ poder da identidade: a era da informação, economia, sociedade e cultura, vol. II. Tradução de Alexandra Lemos. Lisboa: Fundação Calouste Gulbenkian, 2003.

CHARTIER, Roger. O mundo como representação. Revista Estudos Avançados, São Paulo, v. 5, n. 11, jan/abr 1991.

À beira da falésia: a história entre as certezas e as inquietudes. Tradução de Patrícia Chittoni Ramos. Porto Alegre: Editora da UFRGS, 2002.

CORRIGAN, John. The study of religion and emotion. Religion, Social Science Studies of Religion. Oxford, p. 1-11, set. 2009. Disponível em: http://www.oxfordhandbooks.com/view/10.1093/oxfordhb/9780195170214.001.0001/oxfordhb-9780195170214-e-1?print. Acessado em 2 fev. 2017.

CUNHA, Magali. A explosão gospel: um olhar das ciências humanas sobre o cenário evangélico no Brasil. Rio de Janeiro: Mauad X, 2007.

DILHAC, Marc Antoine. La Tolérance, un risque pour la démocratie? Theorie d'un impératif politique. Paris: J. VRIN, 2014.

FRESTON, Paul. Protestantes e a política no Brasil: da constituinte ao Impeachment. 1993. Tese (Doutorado em Ciências Sociais). Universidade Estadual de Campinas, Campinas, 1993.

GIDDENS, Anthony. Globalização e Mundo em mudanças. In. Sociologia. Tradução de Ronaldo Cataldo Costa. Porto Alegre: Editora Penso, 2012.

HALL, Stuart. A questão multicultural. In: Da diáspora: identidades e mediações culturais. Tradução de Adelaine La Guardia Resende. Belo Horizinte: Editora da UFMG, 2003.

A centralidade da cultura: notas sobre as revoluções culturais do nosso tempo. Revista Educação e Realidade, Porto Alegre, v. 22, n. 2, p. 15-46, jul/dez. 1997.

HOOVER, Stewart. Mídia e Religião: premissas e implicações para os campos acadêmico e midiático. Revista C\&S, São Bernardo do Campo, v. 35, n. 2, p. 41-68, jan/jun. 2014.

Religion in media culture. In: MORGAN, David; PROMEY, Sally (Orgs.).Visual Cultures and American Religious. Los Angeles: University of California Press, 2003.

JENKINS, Henry. Cultura da Convergência. Tradução de Susana de Alexandria. 2. ed. São Paulo: Aleph, 2009. 
Cultura da conexão: criando valor e significado por meio da mídia propagável. Tradução de Patrícia Arnaud. São Paulo: Aleph, 2014.

KELLNER, Douglas. A cultura da mídia: Estudos culturais: identidade e política entre o moderno e o pós moderno. Tradução de Ivone Castilho. Bauru- SP: Edusc, 2001.

MARIANO, Ricardo. Neopentecostais: a sociologia do novo pentecostalismo no Brasil. São Paulo: Loyola, 1999.

MARIZ, Cecília Loreto; MACHADO, Maria das Dores Campos. Mudanças recentes no campo religioso brasileiro. Revista de Antropolítica, v. 2, n. 28, p. 21-44, dez. 2007.

RETONDAR, Anderson Moebus. Sociedade de consumo, modernidade e globalização. São Paulo: Annablume, 2007.

SHEEVA, Sarah. Defraudação emocional segundo os princípios bíblicos: como casar com a pessoa certa e evitar o casamento encalhado. 2. ed. Belo Horizonte: Editora Conceição Milagres, 2015.

Recebido em: 21/10/2017 Aprovado em: 27/01/2018 